\title{
A disciplina de Sociologia no contexto da proposta curricular paulista
}

\author{
The subject of Sociology in the context of the \\ "paulista" curriculum proposal
}

Celso Carvalho

Prof. Dr. do Programa de Pós-Graduação em Educação da Universidade Nove de Julho/SP (Uninove). celsocarvalho@uninove.br

\author{
José Humberto da Silva \\ Mestrando em Educação - Universidade Nove de Julho/SP (Uninove). \\ humbertosilva1967@uol.com.br
}

\begin{abstract}
Resumo
Este artigo apresenta os resultados parciais de uma pesquisa que se encontra em fase de conclusão no âmbito da linha de pesquisa em Políticas Educacionais do PPGE da Uninove-SP. Tendo como referência os documentos que apresentam o currículo oficial paulista, seu objetivo é analisar qual é a concepção de "mundo do trabalho" apresentada aos estudantes do Ensino Médio e como esta concepção se manifesta na disciplina de Sociologia. Como elementos norteadores da análise, utilizamos as categorias de estranhamento e desumanização conforme as teorizações de Lessa (2000), que por sua vez se valem das definições postuladas por Lukács, que nos mostra como a proposta curricular, mais do que propiciar condições para a formação crítica, dificulta essa formação na medida em que a análise que faz abstrai e naturaliza os processos sociais.
\end{abstract}

Palavras-chave: Currículo. Desumanização. Estranhamento. Proposta curricular paulista. Sociologia.

\begin{abstract}
This article presents the partial results of a research project that is nearing completion within the research group in Educational Policy at the PPGE at Uninove-SP. Using the documents that present the official curriculum of São Paulo State as reference, its objective is to analyze the conception of the "world of labor" that is presented to middle school students and how this concept reveals itself in the discipline of Sociology. As guiding elements of analysis, we used the categories of strangeness and dehumanization as in the theorizing of Lessa (2000) which in its turn use the definitions postulated by Lukacs, who shows us how the curriculum proposal not only provides conditions for the critical formation but at the same time hinders this formation since the analysis that it makes disregards and naturalizes the social processes.
\end{abstract}

Key words: Curriculum. Dehumanization. "Paulista" curriculum proposal. Sociology.

Strangeness. 


\section{Introdução}

Este artigo tem como base os resultados de uma pesquisa que se encontra em fase de conclusão no âmbito da linha de pesquisa em Políticas Educacionais do PPGE da Uninove-SP, intitulada "O mundo do trabalho no contexto da proposta curricular paulista". Nosso objetivo é analisar o currículo oficial paulista e, com base no binômio "estranhamento e desnaturalização", compreender qual é a concepção de "mundo do trabalho" apresentada aos estudantes do Ensino Médio e como ela se manifesta na disciplina de Sociologia.

A Proposta Curricular paulista, implantada de forma linear em toda a rede estadual de educação básica em 2008 e convertida em Currículo Oficial em 2010, foi fruto do Programa de Ação do Governo Serra para a Educação de 2007, materializado no Projeto São Paulo Faz Escola, que do ponto de vista dos seus idealizadores objetivava "[...] promover melhorias na qualidade da educação e mudar o perfil e os indicadores da educação paulista [. . .]" (SEE, 2008, p. 9), que se encontravam entre os piores do país. O projeto em questão foi apresentado como um conjunto de metas, ações e medidas no contexto do qual a proposta curricular se fundamentava no lema: Uma educação à altura dos desafios contemporâneos e nos Princípios para um currículo comprometido com o seu tempo, que anunciavam e norteavam seus objetivos, a saber:

Uma escola que também aprende; o currículo como espaço de cultura; as competências como referência; prioridade para a competência da leitura e da escrita; articulação das competências para aprender; articulação com o mundo do trabalho. (SEE, 2008, p. 13-26)

De um modo geral, esses princípios se aproximam dos objetivos traçados no texto Quatro pilares da educação para o século XXI, do Relatório da Organização das Nações Unidas para a Educação, a Ciência e a Cultura (UNESCO), que são: $\mathrm{o}$ aprender a conhecer, o aprender a fazer, o aprender a viver juntos e o aprender a ser (DELORS, 1998). Conforme Moraes (2008, p. 269), esses quatro pilares da educação, "[ . . . ] somados, mais recentemente, ao 'aprender a empreender', revela, enfim, uma educação que se restringe a ser uma educação para o trabalho [. . .]." 
O Programa de Ação do Governo Serra para a Educação integrou mais uma etapa do intenso processo de reformas educacionais empreendidas no Brasil a partir da década de 1990. Como parte desse processo reformista, o Projeto São Paulo Faz Escola caracterizou-se por ter promovido alterações significativas no âmbito do currículo, com possíveis impactos na prática escolar e na ação docente. Uma das faces autoritárias desse processo reside no fato de a elaboração ter se dado de forma totalmente centralizada, como obra solo dos intelectuais da Secretaria de Educação paulista, materializando-se em vasto material específico elaborado para a equipe gestora e em material didáticopedagógico direcionado a docentes e alunos, a saber: Cadernos Gestores, Cadernos dos Coordenadores, Cadernos dos Professores e Cadernos dos Alunos. Esses materiais são de uso obrigatório, tanto em relação à gestão do currículo quanto ao desenvolvimento das aulas por docentes e estudantes, e sua aplicação deve ser acompanhada pelo coordenador pedagógico.

Tendo em vista o objetivo deste texto - realizar a análise da concepção teórico-metodológica da proposta curricular de Sociologia -, é importante mencionar que a disciplina de Sociologia ficou marcada por momentos de inclusão e exclusão nos currículos da educação brasileira durante o século XX, tendo sido incluída na grade da proposta curricular paulista a partir de 2009 em decorrência da determinação da Lei no 11.684, de 2 de junho de 2008, que alterou a Lei de Diretrizes e Bases da Educação Nacional (Lei no 9394/96 - LDBEN), tornando-a obrigatória no currículo do Ensino Médio.

Não obstante a determinação desta recente Lei, a LDBEN, no seu Artigo 36, $\S 1^{\circ}$, Inciso III, já havia determinado que "[ . . . ] ao fim ensino médio, o educando deve apresentar domínio de conhecimentos de filosofia e sociologia, necessários ao exercício da cidadania." Porém, em virtude de uma interpretação equivocada, constante das Diretrizes Curriculares Nacionais para o Ensino Médio (DNCEM), do Parecer do CNE/CEB 15/98 (Conselho Nacional de Educação / Câmera de Educação Básica) e da Resolução do CNE/CEB 03/98, foi invertida a expectativa de a Sociologia ter o status de disciplina obrigatória no Ensino Médio, determinandose que seus conteúdos deveriam ser abordados de forma interdisciplinar pelas disciplinas que compõem a grade curricular das Ciências Humanas e mesmo por outras, com o desenvolvimento de conteúdos que pudessem contribuir com a formação cidadã dos educandos. 


\section{Os fundamentos da proposta curricular de Sociologia}

A sociologia constitui um objeto intelectual tenso e contraditório. Para alguns ela representa uma arma poderosa a serviço dos interesses dominantes, para outros ela é a expressão teórica dos movimentos revolucionários. (MARTINS, 2006, p.7).

Os intelectuais da Secretaria de Educação paulista que elaboraram a proposta curricular de Sociologia afirmam, na apresentação, que sua "concepção metodológica" está fundamentada nas "[...] concepções anteriores que orientaram, em diferentes momentos, os estudos, os debates e o ensino dessa disciplina [.. .]"; essas concepções haviam orientado as propostas curriculares das "[...] décadas de 1980 e 1990, quando a Sociologia voltou a fazer parte da estrutura curricular do Ensino Médio [...]” (SEE, 2009, p. 41) e são válidas para o contexto atual.

Referenciando-se no resgate dessas concepções, a proposta de Sociologia anunciada foi apresentada como meio de se construir a ética, a crítica, a consciência e a cidadania:

Assim, reafirmamos, nesta proposta, que a volta da Sociologia ao Ensino Médio apóia-se no reconhecimento de que a democratização do acesso ao conhecimento científico tem na Sociologia, como ciência humana produtora de conhecimentos específicos, uma mediação indispensável para atingir o objetivo de incrementar a participação consciente, racional e bem informada dos cidadãos nos assuntos públicos.

Nesse sentido, a sociologia é entendida, segundo Mannheim, como técnica social, ou seja, como um conjunto de métodos que visam influenciar o comportamento bumano.

Outra influência importante para a elaboração desta proposta advém das Orientações Curriculares Nacionais para o Ensino Médio - Ciências Humanas e suas Tecnologias -, cujo quarto capítulo é destinado à Sociologia. Com elas, compartilhamos a ideia de que o ensino de Sociologia tem como objetivo contribuir para o aprimoramento do educando como 
pessoa bumana, incluindo a formação ética e o desenvolvimento da autonomia intelectual e do pensamento crítico, preparando-o para o exercício da cidadania. (Ibidem, p. 41-42, grifos no original).

Esse enunciado geral identifica-se com um procedimento comum a todo enunciado reformista da década de 1990 e expõe sua face mais contraditória: anunciar o discurso reformista fundado nos auspícios mais gerais da lógica do esclarecimento ao mesmo tempo em que anuncia uma pedagogia das competências que obscurece o conhecimento em detrimento da aprendizagem. Tal contradição é realçada pelo caráter relativista atribuído ao conhecimento, sua ênfase em uma pedagogia cognitivista com tendência à centralidade metodológica.

No âmbito dessa contradição, a proposta curricular anunciada não pode fugir de uma apreciação generalista das questões que se propõe a enfrentar. Assim, anuncia que seu objetivo é o de:

[...] contribuir para a formação do jovem brasileiro, quer aproximando esse jovem da linguagem especial que a Sociologia oferece, quer sistematizando o debate em torno de temas de importância dados pela tradição ou pela contemporaneidade. (Ibidem, p. 42, grifos no original).

Nesse seu intento, a proposta se depara com um de seus limites, qual seja, o uso ampliado do conceito de jovem, como se fosse possível falar em jovem no sentido amplo, como categoria de análise - em nenhuma proposição o texto transforma uma faixa etária em categoria sociológica. Como não explica como procede, resta-nos entender que tal questão não preocupou seus elaboradores. Fica, então, a impressão de que os jovens são todos iguais, não importa se filhos de trabalhadores, das classes médias ou da burguesia.

Apoiando-se nas Orientações Curriculares Nacionais, os elaboradores da proposta de Sociologia estabeleceram que a orientação metodológica para o ensino dessa disciplina deveria se pautar no binômio "estranhamento/desnaturalização", a serem utilizados como fios condutores do processo de ensino-aprendizagem dos conteúdos programáticos estabelecidos para os estudantes do Ensino Médio. No documento, tal questão é assim apresentada: 
O princípio que orienta esta proposta, portanto, é o estranhamento, tal como aparece nas orientações curriculares. Entretanto, isso não se faz sem adotar como orientação metodológica uma Sociologia do conhecimento de inspiração mannheimiana, ou seja, levar a sério e compreender o contexto sócio-histórico que envolve as maneiras como o jovem pensa e vivencia o seu mundo. O objetivo, portanto, é o de colocar o jovem diante do outro, visto como estranho a ele, de forma a permitir-lhe desvendar sociologicamente esse outro. No caso da Sociologia está em causa observar que os fenômenos sociais que rodeiam todos e dos quais se participa não são de imediato conhecidos, pois aparecem como ordinários, triviais, corriqueiros, normais, sem necessidade de explicação, aos quais se está acostumado, e que na verdade nem são vistos.

Novamente recorremos às Orientações Curriculares, destacando essa opção metodológica: Um papel central que o pensamento sociológico realiza é a desnaturalização das concepções ou explicação dos fenômenos sociais. Há uma tendência sempre recorrente a se explicar as relações sociais, as instituições, os modos de vida, as ações humanas coletivas e individuais, a estrutura social, a organização política etc. com argumentos naturalizadores. Primeiro, perde-se de vista a historicidade desses fenômenos, isto é, que nem sempre foram assim; segundo, que certas mudanças ou continuidades históricas decorrem de decisões, e essas, de interesses, ou seja, razões objetivas e humanas, não sendo fruto de tendências naturais. (Ibidem, p. 42-43, grifos no original).

Algumas observações se fazem aqui necessárias. Fica claro no texto que os autores da proposta, ao se referirem à categoria "estranhamento", não o fazem na perspectiva de Lukács, portanto, numa perspectiva marxiana ${ }^{1}$. O ensino de Sociologia proposto reafirma o caráter positivista do pensamento sociológico que embasa o discurso das reformas. Em que pese o anúncio feito de buscar a superação da imediaticidade da análise, tal questão não é aprofundada, ficando meramente restrita ao objetivo de "colocar o jovem diante do outro" sem mencionar quem é esse outro, ou quais relações articulam o "jovem" a esse "outro". Fica-se com 
a impressão de que as categorias estranhamento e desnaturalização ganham autonomia e independência entre si, emergindo de relações abstratas. Retira-se, assim, a possibilidade de compreensão dos fundamentos da proposta de forma a conjugar seus objetivos e a totalidade social que fundamenta sua origem. Nesse sentido, podemos afirmar que os objetivos apontados: possibilitar aos jovens a compreensão do contexto sócio-histórico que determina as formas de pensar e ver o mundo e proporcionar formas de ruptura em relação à cultura hegemônica naturalizada, são impossibilitados por uma lógica que naturaliza os processos sociais e aprofunda o estranhamento.

Esse enfoque positivista da orientação metodológica pode criar dificuldades para que, em seu trabalho, o professor atue como agente da emancipação humana, de modo a contribuir para transformar o pensamento sociológico hegemônico. Ao reduzir o professor à função de "mediador" entre "o conhecimento e os alunos", em "meio" para traduzir os fundamentos do conhecimento científico produzido pela humanidade, a proposta explicita suas contradição e limites. Como contribuir para a formação crítica do aluno se se nega o processo crítico presente no trabalho do professor, notadamente a relação apropriação/ objetivação do conhecimento que lhe permite historicizar a produção do conhecimento e desnudar seu processo de naturalização. O trabalho do professor, agora reduzido à "mediação pedagógica", foi justificado pelos elaboradores da proposta de Sociologia, da seguinte forma:

Busca-se, com isso, discutir o jovem na sua relação de estranhamento com aqueles outros que o envolvem em sua vida cotidiana, em particular, na família, nos vínculos de parentesco e de amizade, na vizinhança, na escola, no lazer e no trabalho. (Ibidem, p. 43-44, grifos nossos).

A categoria "estranhamento" é apresentada aqui de forma positivista, pois fica novamente restrita aos questionamentos que circundam as relações cotidianas dos jovens estudantes com "aqueles outros", sem especificar ou discutir qual a relação desse "outro" com as questões de ordem política, econômica e cultural que permeiam o cotidiano e que são responsáveis pela situação em que se encontra a maior parte dos que frequentam o Ensino Médio. Não especifica e, portanto, naturalizam-se as condições que se produzem no contexto das 
relações desses jovens com a família, com a vizinhança, com a escola, no lazer e, principalmente, no trabalho, as razões que comprometem sua sobrevivência e a de suas famílias.

Nesse delinear, a categoria "desnaturalização", que deveria ser utilizada como propulsora de mudanças na concepção e compreensão dos fenômenos sociais, fica restrita ao objetivo de "se pensar a sociedade em que se vive", sem discutir, no entanto, que sociedade é essa, qual sua origem e características. Não se discute quais são as possibilidades de transformação desta realidade. Embora fale em "desnaturalizar a realidade", aprofunda o processo de estranhamento social por meio da "naturalização" do pensamento sociológico. A manutenção da naturalização da problemática social, na qual se encontram inseridos a maioria dos jovens estudantes do Ensino Médio, é reforçada quando se pensa que a superação do "estranhamento" deve partir dos próprios jovens:

Dessa maneira, o centro de nossas preocupações e o nosso ponto de partida e de chegada é o aluno, o aluno jovem, empenhando-nos para partir dele a fim de, com ele, pensar o sociedade em que vive. Trata-se, portanto, não de se colocar no lugar do jovem como portavoz, mas de aproximar-se dele para estranhar com ele o seu próprio lugar no mundo que o cerca. (Ibidem, p. 42, grifos no original).

A questão que fica é como superar a lógica do estranhamento por meio do conhecimento que possui o ser estranhado, no caso, o aluno. Mais uma vez o que temos é um processo pelo qual palavras e ações bem intencionadas contribuem para pensar a educação numa perspectiva que desvaloriza o conhecer e, nesse sentido, o professor. Próprio das pedagogias escolanovistas, a centralidade no aluno, em que pese seu apelo democrático, contribui apenas para o aprofundamento da lógica que exclui as camadas populares do acesso ao conhecimento que a humanidade produziu. Se a escola é para alguém o único espaço para se apropriar do conhecimento, esse alguém são as camadas populares.

Partindo desse pressuposto, a metodologia para ensino de Sociologia, nos termos em que foi proposta pelas Diretrizes Curriculares Nacionais, contribui com a manutenção do pensamento sociológico hegemônico e é limitadora da transformação social, na medida em que a propositura da categoria "estranhamento" é posta como premissa que implica que o estranhar deve partir do próprio estudante 
como parte do processo de aprendizado, restrita aos limites da sua capacidade e subjetividade. Ao professor resta a função de mediador entre o conhecimento sociológico e o aluno, conhecimento abstrato e não localizado no âmbito das relações sociais. Com isso, a "desnaturalização" dos fenômenos sociais, objetivada pela proposta, fica circunscrita aos limites da cultura hegemônica, quando muito de crítica superficial a essa cultura. A lógica positivista da proposta circunscreve a compreensão da categoria "estranhamento" ao restrito contexto social de convivência cotidiana dos jovens estudantes do Ensino Médio. Não possibilita uma efetiva "desnaturalização" das suas causas por meio de uma perspectiva que historicize o jovem.

A categoria "estranhamento", ao não propor um ensino de Sociologia voltado à "práxis social", acentua também o processo de naturalização que envolve o debate sobre o trabalho, ou sobre o mundo do trabalho, como menciona a proposta. Assim, os elaboradores da proposta, ao proporem tal questão e a possibilidade de a Sociologia contribuir para a compreensão dos jovens sobre as questões que envolvem o mundo do trabalho e, consequentemente, sobre "as possibilidades de acesso dos estudantes ao mercado formal de trabalho", apenas reforçam a perspectiva positivista que possuem. Afirmam eles que:

[...] a situação de desemprego, por exemplo, que atinge os indivíduos em todas as faixas etárias, mais agudamente os jovens, pode ser discutida com os alunos no sentido de mostrar que não se trata de um problema individual, nem muito menos 'natural' nesse segmento da população, decorrente de sua incapacidade ou de seu caráter. Constitui-se, antes de tudo, um problema que possui dimensões que são estruturais e que, resultantes de transformações no mercado de trabalho, apresentam novas exigências quanto à escolaridade e à formação profissional. (SEE, 2009, p. 43, grifos nossos).

A premissa inicial da citação acima até afirma ser o desemprego um fenômeno social, portanto, que não pode ser individualizado. No entanto, ao estabeleceram a relação desemprego a novas demandas de formação e de escolarização, reforçam o que pretendem negar. O desemprego anunciado não é um fenômeno natural, mas as transformações no mercado de trabalho sim. 


\section{Considerações finais}

De um modo geral, é possível afirmar que propostas educacionais centradas na formação para o trabalho e para a cidadania, como é o caso do São Paulo faz Escola, estão fundamentadas em práticas formativas cujos objetivos e finalidades se caracterizam pela lógica da formação de um indivíduo nos limites da prática social cotidiana, do mundo prático, utilitário, imediato, eficaz e eficiente. Essas reformas educacionais almejam a redução do indivíduo a um ser capaz, sim, de desenvolver as mais variadas articulações, habilidades cognitivas e competências, mas no contexto de uma prática social adaptativa para o trabalho, e não pelo trabalho. Não se trata de preocupações com o trabalho, com o processo de trabalho, com o caráter ontológico do trabalho, mas sim com o emprego, com a formação para o emprego, com a adaptação para o emprego e com a incorporação do discurso da empregabilidade.

Outra face do mundo do trabalho no contexto da reforma proposta pela SEE é a de uma educação centrada no desenvolvimento de habilidades e competências como eixo de aprendizagem. A justificativa apresentada é a de que esse "modelo pedagógico" é capaz de permitir que a escola cumpra bem o papel que se espera dela, ou seja, o de promover a formação capaz e apta dos alunos para que eles possam solucionar ou gerir problemas do trabalho, selecionando o modo apropriado de agir dentre as inúmeras possibilidades que se apresentem.

Esta breve análise da proposta curricular para a disciplina de Sociologia nos permite mencionar que a categoria "estranhamento", da forma como é empregada, "naturaliza" as causas do desemprego, limitando sua compreensão às mudanças no mercado de trabalho. Os jovens estudantes do Ensino Médio apresentados são seres abstratos, sem vínculos sociais e produtos de meras relações circunstanciais que se constroem na escola e no trabalho. Nessa proposta não existe classe social e, portanto, não existem contradições sociais. Os problemas apresentados o são como "fenômeno individual e natural", relacionado à condição de ser jovem. Quando são confrontados com as transformações que surgem no "mundo do trabalho" e que passam a exigir maior nível de escolaridade e qualificação profissional, cujas consequências são a redução das possibilidades de acesso ao mercado formal de trabalho, nenhuma menção é feita às razões desse processo. Mudanças no mundo do trabalho, sejam elas quais forem, são apresentadas como uma expressão naturalizada. Práxis social, aqui, é reduzida a adequação social. 
Não há nessa proposta espaço para contradição. E a própria condição de ser jovem se prende a uma definição abstrata, genérica e inespecífica desse segmento etário.

Assim, a forma como as categorias "estranhamento / desnaturalização" são apresentadas, mesmo quando se propõem como críticas de seu tempo, notadamente do mundo do trabalho, acabam naturalizando-o na medida em que não se realiza a crítica às suas causas, o que se evidencia no tratamento (ou não tratamento) da questão do desemprego. Podemos afirmar, então, que a compreensão que se tem do mundo trabalho, na proposta curricular de Sociologia, reafirma os aspectos mais gerais da sociabilidade burguesa. Ao tratar o aluno como um sujeito abstrato e a-histórico, suas relações com o "outro" sem menção a quem é esse "outro" e a referência a um mundo do trabalho que não possui contradições, mas, sim, necessidade de adequação, o que a proposta faz é negar aquilo que se propõe a fazer: orientar sua análise por meio de categorias que auxiliem os jovens a melhor compreender sua realidade social - da forma como anunciam, mais do que ajudar a compreender a realidade social em que esses jovens estão inseridos, aprofundam o processo de estranhamento e desumanização.

\section{Nota}

1 No âmbito da sociabilidade burguesa, a aparência natural das relações sociais entre os sujeitos tende a desaparecer. O processo de reprodução do capital domina e determina o mundo e as relações entre os homens, impondo uma situação em que as ações visam suprir as necessidades de reprodução do capital e não as da generalidade humana. As relações que o capital produz passam a ser a força que impulsiona o agir humano. Transforma, assim, as relações entre os homens em relações que escravizam os homens. Segundo Sergio Lessa (2000, p. 83), esse processo, no âmbito mais geral da práxis social, “[...] dá origem a uma série de complexos sociais que têm a função social de sistematizar os conhecimentos adquiridos em uma concepção de mundo que termine por fornecer, no limite, uma razão para a existência humana. É neste contexto que se desenvolvem os complexos sociais da ciência, da filosofia, da religião, da ética, da estética etc. Portanto, a ideologia, para Lukács, é o conjunto das idéias que os homens lançam mão para interferirem nos conflitos sociais da vida cotidiana. Se as idéias são ou não reflexos corretos da realidade, se e em que medida correspondem ao real, é uma questão que em nada interfere no fato de exercerem uma função ontológica na reprodução 
social. Conceber a ideologia como função social e não como "falsificação do real" possibilita a Lukács superar o mito da "ciência neutra”: se a ideologia fosse sempre e necessariamente a falsa consciência, a "verdadeira" consciência apenas poderia ser a ciência. Deste modo, por uma vertente absolutamente inesperada, terminaríamos na tese, claramente burguesa, da ciência como conhecimento neutro, acima das classes e dos valores, com todos os problemas que advêm de tal posição. É este fenômeno que Lukács denomina de Entfremdung, geralmente traduzido entre nós por Estranhamento ou Alienação. Nada mais é que o complexo de relações sociais que, a cada momento histórico, consubstancia os obstáculos socialmente produzidos para o pleno desenvolvimento humano-genérico.”

\section{Referências}

BRASIL. Ministério da Educação. Lei n. 9.394, de 20 de dezembro de 1996. Estabelece as diretrizes e bases da educação nacional. Disponível em: http://www.mec.gov.br/seb/ ensmed/pcn.shtm. Acesso em: 15 dez. 2011.

Lei $n^{\circ} 11.684$, de 2 de junho de 2008. Altera o art. 36 da Lei n 9.394, de 20 de dezembro de 1996, que estabelece as diretrizes e bases da educação nacional, para incluir a Filosofia e a Sociologia como disciplinas obrigatórias nos currículos do ensino médio. Disponível em: <http://www.planalto.gov.br/ccivil_03/_Ato2007-2010/2008/Lei/L11684. htm. Acesso em: 2 maio 2012.

Parâmetros curriculares nacionais (Ensino Médio) - Ciências Humanas e suas tecnologias. 2000b. Disponível em: <http://www.mec.gov.br/seb/ensmed/pcn.shtm>. Acesso em: 20 nov. 2011.

. PCN+ (Ensino Médio): orientações curriculares e complementares aos

parâmetros curriculares nacionais - Ciências Humanas e suas tecnologias. Disponível em: <http://www.mec.gov.br/seb/ensmed/pcn.shtm>. Acesso em: 18 dez. 2011.

DELORS, Jacques. Educação: um tesouro a descobrir. Relatório para a UNESCO da Comissão Internacional sobre a Educação para o século XXI. Cortez, UNESCO e MEC. Impresso no Brasil, jan. 1998.

Os quatro pilares da educação. Disponível em:

<http://4pilares.net/text-cont/delors-pilares.htm>. Acesso em: 3 jan. 2012.

MARTINS, Carlos Benedito. O que é Sociologia. São Paulo: Brasiliense, 2006 (Primeiros Passos). 
MORAES, Lívia de Cássia Godói. Trabalho, educação e consciência: uma análise do processo de internalização dos parâmetros reprodutivos do capital na atualidade. In: TUMOLO, Paulo Sérgio; BATISTA, Roberto Leme (Org.).Trabalho, economia e educação: perspectivas do capitalismo global. Maringá: Práxis, Massoni, 2008. p. 269-288.

LESSA, Sergio. Lukács e a ontologia: uma introdução. Revista Outubro, São Paulo, v. 5, 2000, p. 83-100.

SECRETARIA DE ESTADO DA EDUCAÇÃO DE SÃO PAULO: Proposta Curricular do estado de São Paulo: Ensino Fundamental (Ciclo II) e Ensino Médio. Coord. Maria Inês Fini. São Paulo: SEE, 2008.

Proposta Curricular do estado de São Paulo: Sociologia / Secretaria da Educação; Coordenação geral Maria Inês Fini; Equipe: Heloisa Helena Teixeira de Souza Martins, Melissa de Mattos Pimenta, Stela Christina Schrijnemaekers. São Paulo: SEE, 2009. Caderno do Professor: Sociologia, Ensino Médio. $2^{\text {a }}$ série, v. 3. Secretaria da Educação; Coordenação geral Maria Inês Fini; Equipe: Heloisa Helena Teixeira de Souza Martins, Melissa de Mattos Pimenta, Stela Christina Schrijnemaekers. São Paulo: SEE, 2009.

recebido em 11 jun. 2012 / aprovado em 25 jun. 2012

\section{Para referenciar este texto:}

CARVALHO, C.; SILVA, J. H. A disciplina de sociologia no contexto da proposta curricular paulista. Dialogia, São Paulo, n. 15, p. 63-75, 2012. 
